\title{
Maximizing the Potential of Information Technology for Management: Strategies for interfacing the Technical Core of Education
}

\author{
C. L. Fulmer
}

Leadership and Educational Policy Studies, Faculty of Educational Administration and School Business Management, Northern Illinois University, DeKalb, IL 60115, USA

\begin{abstract}
The impact of information systems will be maximized when the capacity of the technological architecture and system design are capable of interfacing with the technical core of education. The technical core of education is defined as the interface between the student and the contexts in which they acquire or generate knowledge. The author provides a vision of an integrated information system with (a) multiple input ports, (b) alternative units of analysis for inquiry, (c) variable types of data, (d) choice of analytic processes, and (e) variable access ports for retrieval of data. The author argues that this vision becomes a reality when the system is designed through an inductive process that includes stakeholders from all levels of the organization. To achieve this vision of an integrated information system, educators and information systems specialists need to find ways to integrate the capacity of the information technology with the work and the work life of the technical core and its participants.
\end{abstract}

Key Codes: H.1.2; K.3.1; J.1

Keywords: Information Systems, User/Machine Systems; Computing Milieu, Computer Uses in Education; Computer Application, Administrative Data Processing

\section{INFORMATION SYSTEMS AND EDUCATIONAL IMPACT: AN INTEGRATED VISION}

This paper makes the argument that the potential of information systems will be maximized when the capacity of the technological architecture and system design are capable of affecting the teaching and learning process or the technical core of educational organizations. Much has been written about statistical process controls and productivity in manufacturing facilities but to date not much has been done or has been written about information systems impacting productivity in educational settings. What is required is a shift in focus from the management of information to the support of the work of the technical core, teaching and learning.

\subsection{Instrumental shortfall of existing information systems}

In spite of spectacular technological advances and the recently touted hyperlearning [1] that threatens to make schools as we know them today obsolete, or promises technologically to deschool learning [2], the established educational response has been 
minimal. In spite of the research to the contrary, schools still persist in the process of tracking students through homogenous grouping policies. This is especially unfortunate, since the technology exists to track, instead, the progress of individual students as they work cooperatively in multi-aged, integrated-curricular project work groups. Such a system could provide data that would permit teachers to group students for instruction based on the learning activities of the preceding day. There are many reasons for this current state of affairs, but the consequence is that information systems in educational organizations fall short of the support required for active and productive teaching and learning experiences for teachers and children.

Information tends to be archived rather than data-based. When archieved is typically not readily available to the decision makers. For example, attendance information might be codified and stored in a system that has no interface with educational productivity data: test scores, grades, norm referenced achievement data, or criterion referenced cognitive, affective, or psychomotor skills. Similarly, educational expense data, balanced and organized by quarterly or annual budget deadlines have no interface with units or measures of student learning. Therefore, information systems while meeting the expectation of storing student productivity data and other relevant information, have not had much of an impact on educational productivity.

\subsection{Misplaced focus on management of information}

Perhaps the best explanation for this problem was offered by Zuboff [3] in her work on how computers alter the work of organizations. Technology can be used to automate the processes of the present day to day operations. The process of automation serves to perform tasks with great speed and accuracy. In schools where the atiendance process has been automated another level of bureaucratic paperwork has been created in order to keep the system functioning. When attendance was manually derived, each teacher kept records at her desk on a paper spreadsheet register. Student attendance or non attendance was recorded for a yearly attendance period. At the end of the year, this summary data was transferred by hand to a building record. Next, building records were aggregated, by hand, at the district level. The automated system of taking attendance required teachers to send daily attendance lists to central office. A clerk was then hired to enter the attendance information into a computer. The reports generated by this technology were purposely designed to be identical to the original paper and pencil record. In the automated mode, computers calculated daily average attendance data by class, building, and district at a much faster rate. However, inspite of the speed and accuracy in calculations, the intent of the system to manage the information remained the same.

A more productive way of using technology in this attendance example is what Zuboff [3] called the process of informatingor the process of using information to reconfigure work and the social relationships of production. In the attendance example outlined above, a system that informated would provide more information than average daily attendance figures. Instead, it would illuminate patterns of attendance of individual students that are related to days of the week, times of the year, teacher testing patterns, or other relevant variables that would affect student behavior and productivity. In the original manual attendance method, only the individual classroom teacher had access to the attendance data. In the second, or automated method, only the clerk responsible for attendance input data had access to the information. If attendance data were entered into an informating system, the work surrounding the processes of taking attendance would be 
altered. As altered, the new work would serve both the teacher and administrator in the educational use of these data. Unfortunately, when and if technology is used in schools, it is typically in the mode Zuboff described as automated.

\subsection{Analytic power of an integrated system}

An integrated information system is defined in this paper as one that integrated the processes of automation with the processes of informating. Visscher [4] claimed that soon computer applications for schools will be developed that make new forms of decision support a reality. Relational databases and fourth generation languages become policy making tools when they are utilized to make sense out of system data. For example, the system could be used to find the relation between attendance data, truancy figures, scheduling practices, and student productivity data.

The first step in achieving this vision is to design a system with the potential for multiple input ports. In the attendance example, the manual method of taking attendance impeded the administrative use of the data at the building or district level. Data was not available except at specific report period times. However, the automated system, while convenient for administrative use, removed data from the domain of the teacher's decision making sphere. A system designed with multiple ports of access for entry and retrieval of data would permit information systems to function in an informating as well as in an automating mode.

Secondly, the system must be capable of aggregating data into alternative units of analysis for purposes of inquiry. In addition to attendance coded at the individual student level, other units of analysis such as ethnic, gender, or socio-economic economic status could be used to aggregated data for purposes of system inquiry. Are there specific groups of students either attending or absenting classes. Rather than merely managing data, an integrated system should be capable of generating answers to questions asked by policy makers, building principals, or teachers concerned by attendance patterns of individual children, groups or categories of children, or organizational divisions within a particular school district.

A third step in designing an integrated information system is to provide for multiple types and forms of data: (a) nominal, (b) ordinal, (c) interval ratio, (d) qualitative, (e) biographic, (f) self-evaluation data, (g) samples of writing, (h) student journals, parent feedback, or (j) other forms of student attitude, performance, or productivity. As technology becomes simultaneously more powerful, smaller, and more transportable, learning environments could be networked. Traditional student materials, paper, sketchbooks, notebooks could be replaced by electronic data entry screens. Work in progress, student answers, test scores, verbal responses, and patterns of responses could be data-based for subsequent or instantaneous analyses by from multiple organizational levels.

Alternative types of data and variable units of analyses provide the potential for the fourth step in this integrated information system, the choice of analytic process. It is necessary for members of different organizational levels to require different types of data for decision making [5]. It is also necessary, although difficult for different levels of inquiry to require different modes of inquiry [6]. Would summary data be appropriate for making this decision? Or is descriptive information what is required for this type of problem? Would time analysis data provide more useful information for this particular issue? Or does the issue in question require multiple modes of inquiry and multiple types of analyses as well? 
An integrated information system as defined in this paper would provide for analytic process choices.

Finally, an integrated system would need to provide users with variable levels of access for retrieval of data or data analyses. The technical core of education, or the student and learning environment interface, requires enormous amounts of decision making on the part of the teacher. An integrated information system would provide the support for analytic decision processes of system data at any organizational level. When designed in this manner, decisions at the classroom level are valued as being just as salient as those decisions made at the policy levels of the organization.

\subsection{Simultaneous construction from multiple organizational levels}

An integrated information system is the missing link between the administration of an educational organization and the contexts of learning. This process of knowledge acquisition or generation can be monitored or guided by the integrated system described in this paper.

This system however, must be generated by members from every functional level of the organization. The process of generating each information system will alter the way the work is presently conducted in that particular organization. Administrators, teachers, and students will take on new roles [7]. Students will become more active participants in the data input processes as they participant in learning activities. In any event, this vision becomes a reality when the system is designed through an inductive process that includes stakeholders from the technical core through the executive and policy levels. Strategic planning processes are imperative and will need to focus on multiple and simultaneous levels of input, analysis, and data retrieval [8] to and from the technical core of educational organizations.

\section{THE POWER OF INTERFACING WITH THE TECHNICAL CORE}

The educational impact of information systems will be maximized when the capacity of the technological architecture and system design is capable of interfacing with the technical core of education. Much of what teachers do is invisible to an observer. Decision making many times is intuitive and based on thousands of other decisions made by the teacher's human computer, the brain. Quite often we mistakenly require, encourage, or demand that teachers reduce this rich and conceptually complex data to letter grades as a direct result of the sociological power of the report card. The technical core is the very heart of the education process. An integrated system has the potential to support teachers' and administrators' work. Information systems can rescue complex student data before it is reduced for administrative purposes or parental convenience.

\subsection{The technical core of education defined}

The technical core of education has been defined in this paper as the interface between the student and the contexts in which they learn or generate knowledge. Thompson [9] describes three types of technical cores of complex organizations: (a) long-linked, (b) mediating, and (c) intensive. Schools exhibit characteristics of all three. Creating the interface with a long-linked technical core is the easiest to achieve. Characteristics of this type include serial interdependence, repetition, a constant rate of production, and standardization. Examples of school data of a long-linked nature would be report card 
grades, yearly test data, and medical records. Presently, many information systems are long-linked systems designed for the management of information.

The second type, the mediating technical core, is described as operating in standardized ways with multiple clients or consumers distributed in time and space. Examples of data from a mediating technical core would be information on specific types of groups of students. For example: (a) third, eighth, and eleventh grade achievement test data, (b) pre-school admissions testing results, (c) physical examination records, and/or (d) special education student's individualized education plans (IEPs). While slightly more complicated, the interface required for the mediating technical core is similar to the long linked technology. Once constructed, these automated information systems operate over time, routinely, with multiple types, groups, or levels of data. Systems designed to interface with long-linked or mediating types of technical cores, unfortunately are designed to function as automated systems.

\subsection{The missing link: An interface with the intensive nature of the technical core}

The intensive technical core, as described by Thompson [9] is quite different from the first two. He compares it to an emergency room in a hospital where feedback from the patient is used to determine which treatment from a variety of treatments is appropriate for the medical problem. The characteristics of an intensive technical core sound very much like the description of Zuboff's [3] term informating. The technical core of education organizations in reality function in an intensive fashion even though they are structurally conceived of as long-linked and mediating processes. The intensive type of technical core would be best served by the integrated information systems described above. Such a system would be able to automate and informate. However, it is much easier to develop the integrated system than it will be to actually develop and implement an interface an intensive technical core. But this is exactly what must be done if information systems are to maximize their potential to impact education organizations. The interface will make it possible for the integrated system and its human partners to collect data, automate processes, and informate the work of multiple decision makers from different organizational levels. While a few of these systems may exist in various stages of development, they are largely absent from educational organizations. This author argues that the level of educational impact of an information system is enhanced when the system is able to accommodate the dual processes of automating and informating. Such a system is in fact integrated and therefore capable of interfacing with the complexities of the intensive technical cores found in educational organizations.

\subsection{Building a system that supports the work of the technical core}

In order to create a systems as envisioned above, the system must be designed to support and inform the work of the technical core. The process of automating the work tha is presently being done will precede the work on informating and potentially alter the actua. work of the technical core. As teachers and students gain access to the complexities of teaching and learning processes and products through an integrated information system, decisions that affect learning could be made minute by minute as opposed to quarterly or annually. Work processes would more closely approximate the intensive type of technical core described by Thompson [9]. When we are able to merge the realities of technology and the educational work of teaching and learning, we will have achieved an integrated 
information system that supports the work of the technical core and therefore impacts educational productivity.

\section{ISSUES FOR EDUCATORS AND INFORMATION SPECIALISTS}

In order for technology to interface with the technical core of educational organizations, educators and technologists or information systems specialists need to merge the realities of each of their worlds. The teachers and administrators need to become acquainted with the capacity of the software and hardware of integrated information systems. Accordingly, information systems specialists need to start at each level of the organization and draw out the complexities of present modes of working to determine how the technology can be used for the purposes of informating the work environment. The process of creating the system envisioned in this paper will modify the realities of both the work environment and the design of the information system. When an inductive process is brought to bear on the problems of integrating technology with educational productivity, information systems will move beyond the management information, move beyond automating existing practices, and move toward informating or maximizing the potential of information systems to affect the technical core of educational organizations.

\section{References}

1. Perelman, L. J. (1992). School's out: Hyperlearning, the new technology, and the end of education. New York: William Morrow and Company.

2. Haas, J. D. (1988). Educational futures: Six scenarios, In. J. L. Burdin, (Ed.) School leadership: A contemporary reader. Sage Publications, Newbury Park, California.

3. Zuboff, S. (1988). In the age of the smart machine: The future of work and power. New York: Basic Books.

4. Visscher, A. J. (1993). The computer as an administrative tool: Problems and impact, Journal of Research on Computing in Education, 21(1), 28-35.

5. Somerset, A. and Ekholm, M. (1990). Different information requirements for different levels of decision-making, In. K. N. Noss and L. Mahlck (Eds.), Planning the quality of education: The collection and use of data for informed decision-making, Pergamon, Oxford, England.

6. Windham, D., Levin, H., and Bathory, Z. (1990). Issues in the design and development of educational information systems, In K. N. Noss and L. Mahlck (Eds.), Planning the quality of education: The collection and use of data for informed decision-making, Pergamon, Oxford, England, 1990.

7. Kearsley, G. and Lynch, W. (1992). Educational leadership in the age of technology: The new skills. Journal of Research on Computing in Education, 25(1), 50-60.

8. Carter, R. B., Nilankanta, S. and Norris, D. (1993). Strategic planning for information systems: The evidence from a successful implementation in an academic setting, Journal of Research on Computing in Education, 24(2), 280-288.

9. Thompson, J. D. (1967). Organizations in action. New York: McGraw Hill. 